\title{
Numerical Simulation of a Magnetocaloric Heat Pump for Domestic Hot Water Production in Residential Buildings
}

\author{
Hicham Johra ${ }^{1}$, Konstantin Filonenko ${ }^{2}$, Anna Marszal-Pomianowska ${ }^{1}$, Per Heiselberg ${ }^{1}$, Christian \\ Veje $^{2}$, Stefano Dall'Olio ${ }^{3}$, Kurt Engelbrecht ${ }^{3}$, Christian Bahl ${ }^{3}$ \\ ${ }^{1}$ Aalborg University, Aalborg Øst, Denmark \\ ${ }^{2}$ University of Southern Denmark, Odense M, Denmark \\ ${ }^{3}$ Technical University of Denmark, Roskilde, Denmark
}

\begin{abstract}
Previous studies showed that magnetocaloric heat pump, based on the active magnetic regenerator technology, can be used for space heating of low energy buildings. This innovative solution has performances comparable to conventional vapour-compression systems. However, magnetocaloric heat pumps have limited temperature span between heat source and heat sink. That compromises their use for high temperature span purposes such as domestic hot water production. To overcome this issue, the authors suggest a cascading configuration of several magnetocaloric heat pumps. The results of the current numerical study show that such cascading network can provide for the hot water needs of a single-family house with coefficient of performance which is similar to conventional heat pump systems.
\end{abstract}

\section{Introduction}

In countries with dominating building heating demand, heat pump systems are found to be an economically and environmentally optimum solution for indoor space conditioning and domestic hot water (DHW) production (Cockroft and Kelly, 2006; Lund et al., 2010; Palzer and Henning, 2014). Consequently, they are a key component of the energy development of countries willing to achieve high energy efficiency and sustainability for their building stock. In response to the sustained growth of the heat pump market (Nowak and Westring, 2015), research groups continuously strive to develop and improve cost-effective solutions for heating and cooling applications.

The current heat pump market is dominated by vapourcompression systems. This mature heat transfer technology has proved its cost-effectiveness for building heating / cooling purposes with appreciable coefficient of performance (COP) commonly ranging from 3 to 5 (Self et al., 2013; Fischer and Madani, 2017). However, there are several promising alternatives to conventional vapour-compression devices (Goetzler et al., 2014). Among them, devices employing the caloric effects of solid refrigerant materials in an active regenerative cycle with a sustainable heat transfer fluid have been gaining attention over the last few years. Caloric effects are large adiabatic temperature changes in a material caused by a transition applied field and can be accompanied by a phase change. The latter can be induced in the refrigerant material by either a variation of the electrical field: electrocaloric effect (Plaznik et al., 2019); a variation of the hydrostatic pressure: barocaloric effect (Mañosa et al., 2010); a variation of the uniaxial mechanical stress: elastocaloric effect (Tušek et al., 2015); or a variation of the magnetic field: magnetocaloric effect (Smith et al., 2012). Although they have yet to prove their competitiveness, caloric effects could be a viable alternative to conventional vapour-compression systems to transfer thermal energy from a low-temperature heat source to a hightemperature heat sink without any toxic, flammable, greenhouse effect or fluorinated gases.

Among the aforementioned caloric effects, the magnetocaloric technology is currently the most studied and mature of all. Since the discovery of the magnetocaloric effect (MCE) a century ago by Weiss and Piccard (1918), several research teams have developed prototypes for magnetic cooling near roomtemperature (Engelbrecht et al., 2012; Jacobs et al., 2014; Aprea et al., 2015). These magnetocaloric devices can generate up to 2 or $3 \mathrm{~kW}$ of cooling / heating power with COPs approaching or above 3, and temperature span up to $25 \mathrm{~K}$.

In line with the general efforts to develop new efficient heating systems, the ENOVHEAT project aims at engineering, building and testing the prototype of an innovative magnetocaloric heat pump (MCHP) for building applications (Bahl, 2015). A previous numerical study showed that an MCHP can be coupled to a ground source heat exchanger (GSHE) and a radiant under-floor heating (UFH) system in a single hydronic loop, and provide for the space heating needs of a low-energy house in Denmark (Johra et al., 2018). It can produce up to $2600 \mathrm{~W}$ of heating power with a COP of 3.93. In conventional heat pump systems, the operational parameters are kept within an optimum range and the inefficient start / stop cycles are minimized thanks to the use of a buffer hot water storage tank. However, in the case of the magnetocaloric indoor space heating system, there is no buffer tank. Instead, the thermal energy is stored in the thermal mass of the built environment by means of indoor temperature set point modulation control. It enables the increase of the MCHP running time at highest COP and thus improves the overall seasonal efficiency of the magnetocaloric heating system (Johra et al., 2019a). 
These results are encouraging for the development of energy efficient magnetic heating applications in buildings. However, these MCHP systems have a restricted temperature span. If a $30{ }^{\circ} \mathrm{C}$ fluid supply temperature is sufficient for heating up the indoor space of a low-energy house, it is not enough for the higher temperature purposes such as DHW production at $60^{\circ} \mathrm{C}$. This limitation can be overcome by using a higher temperature heat source such as a low-temperature district heating network. The latter provides direct heat to a low-temperature indoor space heating system while the heat pump is used as a booster for DHW production (Østergaard and Andersen, 2018). Nonetheless, in the case of a colder heat source, such as GSHE, where a large temperature span must be generated, cascading MCHPs can be a viable solution (Filonenko et al., 2018; Johra et al., 2019b).

The aim of the current numerical study is to extend the previous research of the ENOVHEAT project and investigate the use of cascading configurations to increase the temperature span of MCHP for DWH production. Firstly, the operational principle and characteristics of the magnetocaloric heating system are introduced. The numerical models for the different building systems are then presented. The efficiency of the cascaded MCHP is then assessed for DHW production in a Danish single-family house. Lastly, a conclusion and suggestions for further scientific investigations close this article.

\section{Magnetocaloric heat pump}

\section{Working principle of the magnetocaloric system}

As mentioned before, some specific materials exhibit a large reversible temperature change when they are subjected to an adiabatic magnetization or demagnetization. They are called "magnetocaloric materials" (MCM) (Smith et al., 2012). These MCMs can be used as a solid refrigerant in an active magnetic regenerator (AMR) thermodynamic cycle to perform thermal energy transfer from a cold heat source to a warm heat sink with a temperature span larger than the adiabatic temperature change of the MCE (Barclay and Steyert, 1982).

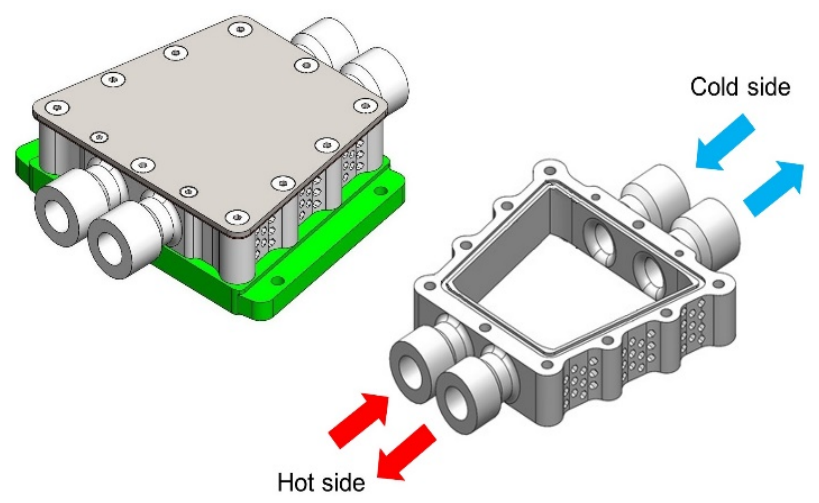

Figure 1: Active magnetic regenerator containing the MCM solid refrigerant.

The MCM refrigerant is contained as a porous medium inside regenerators allowing bi-directional circulation of a coolant fluid through the former to transfer heat within the system (see Figure 1). The MCM is alternatingly magnetized and demagnetized by an external magnetic field source, in this case a rotating permanent magnet (see Figure 2 and Figure 3).

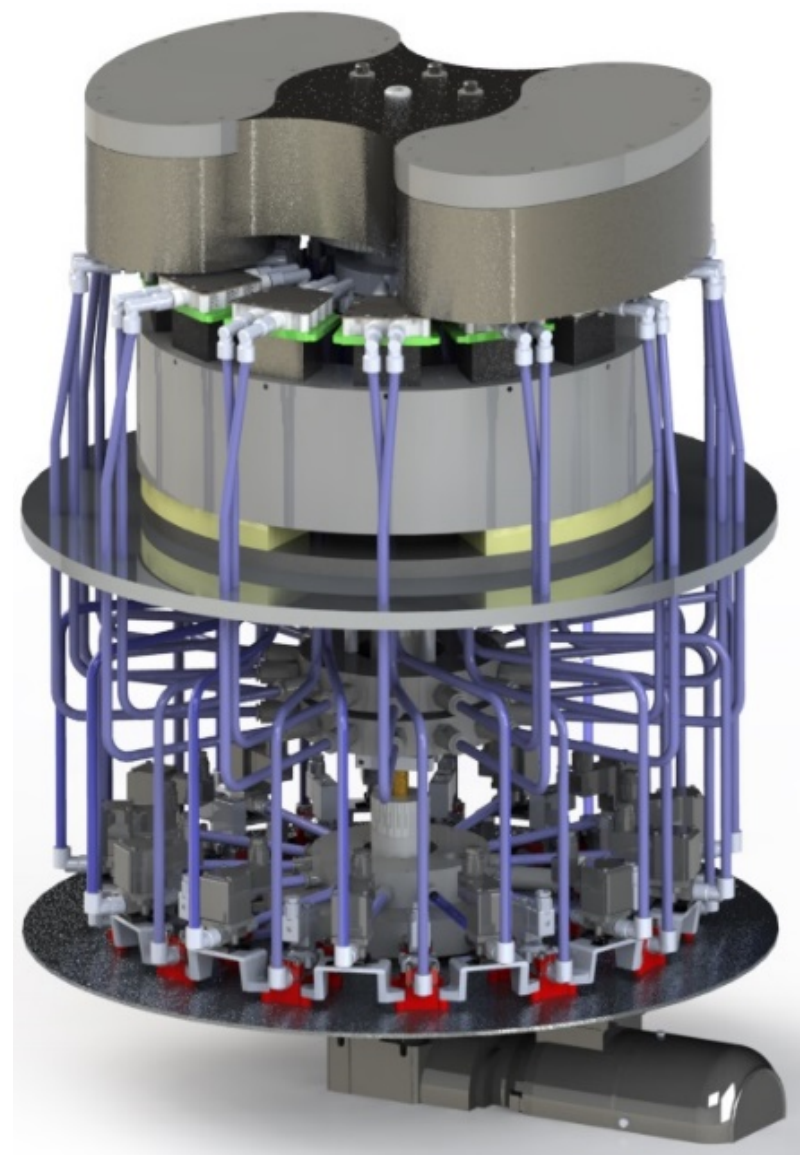

Figure 2: CAD model of the magnetocaloric heat pump prototype of the ENOVHEAT project: "MagQueen".

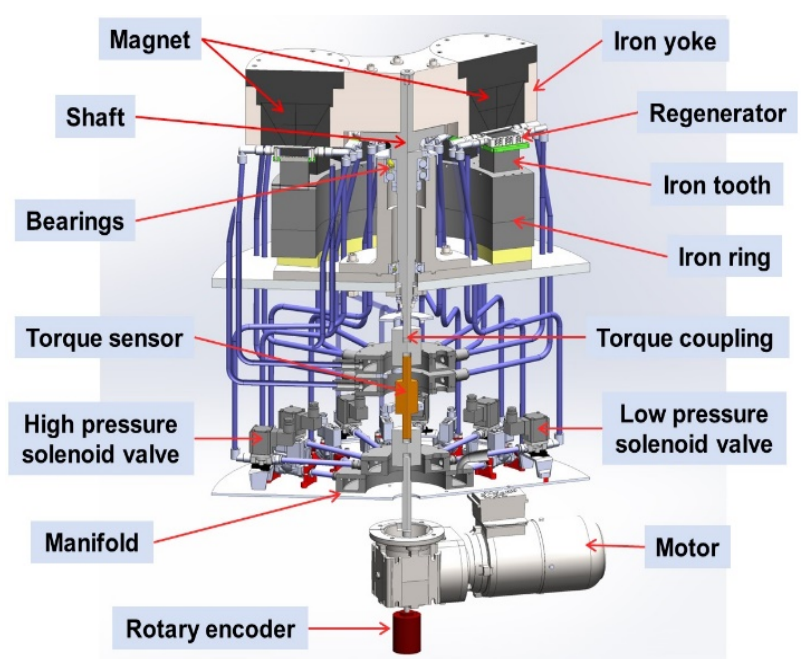

Figure 3: Description of the magnetocaloric heat pump prototype of the ENOVHEAT project: "MagQueen".

Gadolinium $(\mathrm{Gd})$ is a well-known rare-earth element which is considered to be the reference MCM near room-temperature. When magnetized in the vicinity of its Curie temperature (293 K), Gadolinium exhibits a 
large adiabatic temperature change (Smith et al., 2012). However, there are some alternatives to this rare-earth element, such as the intermetallic compound $\mathrm{La}(\mathrm{Fe}, \mathrm{Mn}, \mathrm{Si})_{13} \mathrm{H}_{\mathrm{y}}$. This material family also presents a large $\mathrm{MCE}$ at near room-temperature, but it is composed of elements which are more abundant and low-cost than Gadolinium. Moreover, the Curie temperature (temperature at which the MCE is maximum) of the $\mathrm{La}(\mathrm{Fe}, \mathrm{Mn}, \mathrm{Si})_{13} \mathrm{H}_{\mathrm{y}}$ can be finely adjusted to match the inherent temperature gradient inside the active magnetic regenerator, and thus improve the efficiency of the MCHP. AMR with adjusted MCM Curie temperature along their length are called "graded" or "multi-layered" regenerator (Navickaite et al., 2018).

An overview of the MCHP operation can be found in Johra et al. (2018). For an extensive explanation of the magnetocaloric effect and magnetic heating / cooling devices, the reader is invited to refer to Smith et al. (2012), Engelbrecht et al. (2012) and Kitanovski et al. (2015).

\section{Magnetocaloric heat pump characteristics}

The MCHP of this numerical study is a rotary AMR system (see Figure 2 and Figure 3). The trapezoidal shaped-cassette active magnetic regenerators containing the MCM are mounted on an iron ring and compose the vertical stator. The length of a regenerator is $20 \mathrm{~cm}$. The vertical rotor is a two-pole permanent magnet assembly. It is connected to an electrical motor by a vertical shaft. The rotation frequency of the magnets can vary from $0.25 \mathrm{~Hz}$ up to $4 \mathrm{~Hz}$. However, in the current study, rotation frequency is fixed at $2 \mathrm{~Hz}$. The maximum value of the magnetic field inside the regenerator is 1.46 Tesla (during magnetization of the MCM). The regenerators are connected to 2 manifold distributors and 2 manifold collectors. One of each for the cold heat source and for the warm heat sink. A set of synchronized solenoid valves and check valves control the bi-directional flow of the coolant fluid (water-based brine with Entek FNE as corrosion inhibitor) through each regenerator (Johra, 2018).

The MCM solid refrigerant of this MCHP is the intermetallic compound $\mathrm{La}(\mathrm{Fe}, \mathrm{Mn}, \mathrm{Si}){ }_{13} \mathrm{H}_{\mathrm{y}}$. The Curie temperature of the compound is adjusted within the 23 layers of MCM along the length of the regenerator so that the MCE is maximum at the different operational temperatures inside the AMR.

\section{Numerical modelling of the magnetocaloric heat pump}

The core of the MCHP modelling is the calculation of the heat transfer fluid temperature in the active magnetic regenerator as function of different operational parameters such as fluid flow rate, MCM properties, inlet fluid temperatures, regenerator's geometry, magnetic field, rotation frequency, etc. A detailed numerical model of the AMR was created by Engelbrecht (2008), and then further developed by Lei et al. (2017). With reasonable assumption on heat losses, regenerator's geometry and demagnetization losses, the time-dependent temperature of the heat transfer fluid in the regenerator is calculated with the two following coupled partial differential equations:

$$
\begin{aligned}
& \quad \frac{\partial}{\partial x}\left(k_{\text {disp }} A_{c} \frac{\partial T_{f}}{\partial x}\right)-\dot{m}_{f} c_{f} \frac{\partial T_{f}}{\partial x}-\frac{N u k_{f}}{d_{h}} a_{s} A_{c}\left(T_{f}-T_{s}\right) \\
& +\left|\frac{\partial P}{\partial x} \frac{\dot{m}_{f}}{\rho_{f}}\right|=A_{c} \varepsilon \rho_{f} c_{f} \frac{\partial T_{f}}{\partial t}
\end{aligned}
$$

$\frac{\partial}{\partial x}\left(k_{s t a t} A_{c} \frac{\partial T_{s}}{\partial x}\right)+\frac{N u k_{f}}{d_{h}} a_{s} A_{c}\left(T_{f}-T_{s}\right)$

$=A_{c}(1-\varepsilon) \rho_{s} \times\left[c_{H} \frac{\partial T_{S}}{\partial t}+T_{S}\left(\frac{\partial s_{S}}{\partial H}\right)_{T_{S}} \frac{\partial H}{\partial t}\right]$

Where $k, T, \rho, c$ and $\partial s / \partial H$ are the thermal conductivity, temperature, density, specific heat, and change of entropy with change of magnetic field at constant temperature; $A_{c}, d_{h}, a_{s}, \varepsilon, x, t, \dot{m}_{f}$, and $H$ are the cross sectional area, hydraulic diameter, specific surface area, porosity of the regenerator bed, axial position, time, fluid mass flow rate and internal magnetic field; $\partial P / \partial x$ and $N u$ are the pressure drop and the Nusselt number. The subscripts $f$ and $s$ represent fluid and solid refrigerant, respectively. $k_{d i s p}$ is the thermal conductivity of the fluid due to axial dispersion, $k_{\text {stat }}$ is the static thermal conductivity of regenerator and fluid matrix, and $c_{H}$ is the specific heat capacity of the MCM at constant magnetic field. These partial differential equations are solved with an implicit finite volume method scheme.

Although this detailed numerical model is accurate and has been validated with experimental data from MCHP prototypes (Lei et al., 2018), it is too computationally demanding for a direct implementation in a building energy simulation tool. It is therefore approximated by 5-dimentional interpolation lookup table functions containing around 1600 output points generated by the detailed model. These lookup table functions therefore form a simplified model for the MCHP with 4 input variables (rotation frequency, volumetric fluid flow rate, cold side temperature inlet and hot side temperature inlet) and four output variables (cold side outlet fluid temperature, hot side outlet fluid temperature, magnetic work and fluid pressure losses through the regenerators).

The other components of the magnetocaloric system (valves, motor, circulation pump) are modelled with simple functions fitting data from measurements on MCHP prototypes and from manufacturers documentation (Johra, 2018).

\section{Cascading of magnetocaloric heat pumps}

As previously mentioned, the limited temperature span generated by a single MCHP can be overcome by establishing a parallel cascaded network of several MCHPs. As illustrated in Figure 4, the hot fluid outlet of a MCHP is connected to the hot fluid inlet of the next MCHP in the cascade. Conversely, the cold fluid outlet of a MCHP is connected to the cold fluid inlet of the next MCHP in the cascade. At each stage of the cascade, the cold fluid is cooled down, and its thermal energy is transferred to the hot fluid which is heated up. Consequently, the temperature span increases after each 
MCHP in the cascade (Filonenko et al., 2018; Johra et al., 2019b).

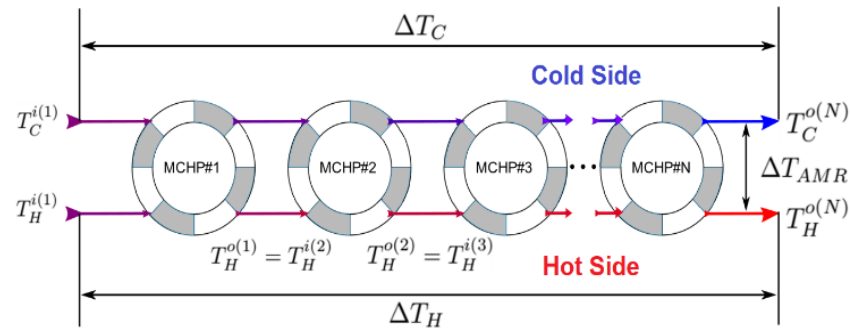

Figure 4: Cascading connection diagram: hot-to-hot and cold-to-cold.

In this study, 5 different cascaded MCHP configurations are investigated:

- 2 cascaded MCHPs with 12 regenerators each.

- 4 cascaded MCHPs with 6 regenerators each.

- 6 cascaded MCHPs with 4 regenerators each.

- 12 cascaded MCHPs with 2 regenerators each.

- 24 cascaded MCHPs with 1 regenerator each.

The total mass of MCM in each cascaded configurations is kept constant at $5.24 \mathrm{~kg}$.

\section{Building systems}

\section{Building study case}

The main goal of this numerical study is to investigate the capacity of a MCHP to produce DHW in a Danish single-family house. The magnetic heating device is thus integrated in a hydronic loop connecting a vertical borehole GSHE with a $250 \mathrm{~L}$ hot water storage tank (see Figure 5).

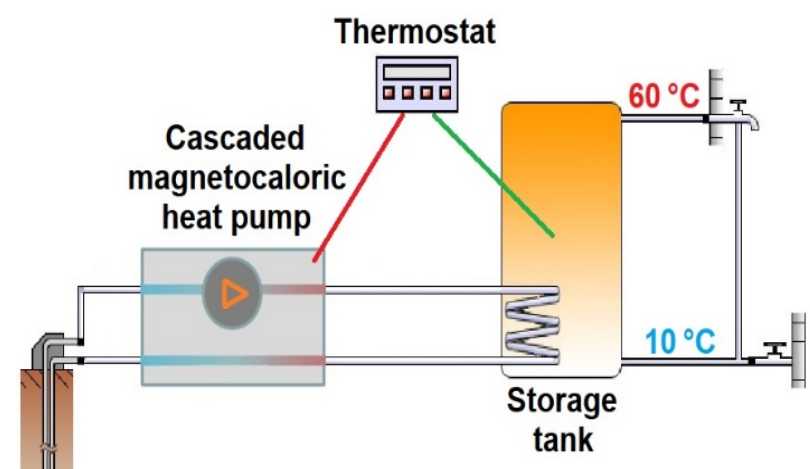

\section{Ground source}

Figure 5: Integration of a magnetocaloric heat pump for domestic hot water production.

The GSHE loop is a vertical borehole consisting of a single collector double U-tube PEX pipe (44 mm diameter). The borehole itself is $100 \mathrm{~m}$ deep and has a diameter of $160 \mathrm{~mm}$. The thermo-physical properties of the soil surrounding the ground source loop are assumed to be the ones of a humid clay sand (thermal conductivity of $1.5 \mathrm{~W} / \mathrm{m} . \mathrm{K}$, density of $1900 \mathrm{~kg} / \mathrm{m}^{3}$, specific heat capacity of $1400 \mathrm{~J} / \mathrm{kg} . \mathrm{K}$ ), which is a typical ground in Denmark. The grouting material in the borehole has a thermal conductivity of $1.4 \mathrm{~W} / \mathrm{m} . \mathrm{K}$, a density of $1500 \mathrm{~kg} / \mathrm{m}^{3}$ and a specific heat capacity of $1670 \mathrm{~J} / \mathrm{kg}$.K. The typical fluid temperature outlet of the GSHE is around $8{ }^{\circ} \mathrm{C}$.
The hot water storage tank has a cylindrical shape (radius of $29 \mathrm{~cm}$ and height of $95 \mathrm{~cm}$ ) with $5 \mathrm{~cm}$ of polyurethane insulation. The heat losses from the storage tank to the ambient environment are therefore $1.356 \mathrm{~W} / \mathrm{K}$. The stainless steel heat exchanger coil inside the storage tank is placed in the lower half of the latter, and has a total surface area of $1 \mathrm{~m}^{2}$.

The heat pump system is regulated by a thermostat connected to a temperature sensor located in the middle of the hot water storage tank. The thermostat is an ON/OFF controller (heat pump is either off or running at constant pre-set fluid flow rate) with a dead band temperature set point: lower temperature threshold of $58{ }^{\circ} \mathrm{C}$; upper temperature threshold of $60{ }^{\circ} \mathrm{C}$.

In order to simulate realistic DHW needs of a singlefamily in a Danish house, a detailed time-dependent hot water consumption profile is needed. However, there is a clear lack of information concerning hot water draw-off profiles with high temporal resolution (Fuentes et al., 2018). Therefore, the total hot water draw-off at $60{ }^{\circ} \mathrm{C}$ has been monitored at the production point in a singlefamily house in Denmark (2 adults and 2 kids). The hot water flow rate was measured with an ultrasonic flowmeter (KATflow 100 Ultrasonic Flow Transmitter) at a sampling rate of 1 second. In this way, the hot water draw-off profile has been obtained for the month of September 2018 with a time resolution of 1 second (see Figure 6). The average DHW consumption (at $60^{\circ} \mathrm{C}$ ) of this family is around $97 \mathrm{~L} /$ day, which is a typical value in Europe (Fuentes et al., 2018). Moreover, peak DHW consumption is ranging from $6 \mathrm{~L} / \mathrm{min}$ to $14 \mathrm{~L} / \mathrm{min}$, which coherent with typical values for European countries (Fuentes et al., 2018).

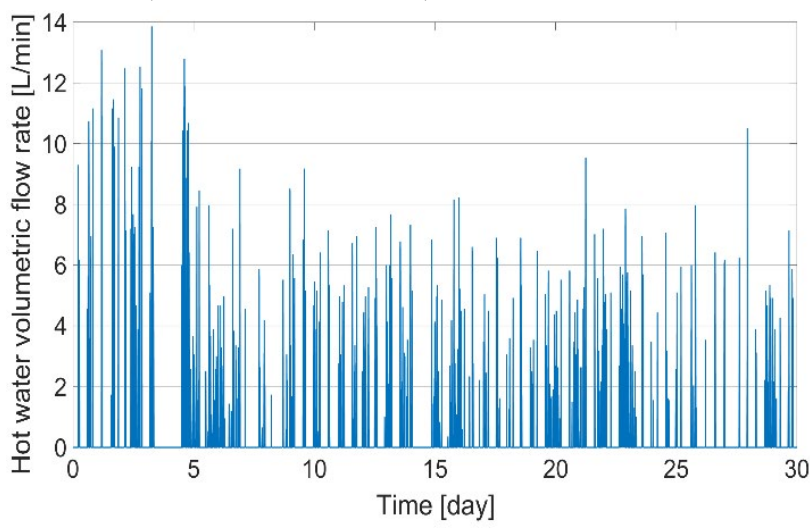

Figure 6: Domestic hot water consumption profile for a single-family house in Denmark during September 2018 (1-second time resolution).

The fresh cold water supply to the bottom of the storage tank is assumed to be at the temperature of the underground yearly average temperature (Fuentes et al., 2018). The latter is $10^{\circ} \mathrm{C}$ in Denmark (Johra, 2018).

\section{Numerical modelling of the building systems}

The simplified numerical models of the cascaded MCHPs, together with the other building systems for DHW production, have been created and implemented within the MATLAB-Simulink software environment. 
The vertical borehole GSHE is simulated by coupling a "plug flow" model and the $\varepsilon$-NTU method. The $\varepsilon$-NTU method allows the calculation of the effective heat transfer between the brine and the ground surrounding the borehole, taking into account the interaction between the two legs of the GSHE. The thermal interactions between the GSHE tubes and the grouting are modelled with a triangular thermal network (ResistanceCapacitance thermal network). A MATLAB state space function simulates the underground soil surrounding the borehole as a one-dimensional finite domain. Boundary conditions are determined by the outdoor weather conditions on the upper ground surface and the lateral surface of the finite underground domain. The boundary condition at the bottom surface of the underground (100 m depth) is set to a constant temperature of $10.1{ }^{\circ} \mathrm{C}$. The "plug flow" model accounts for the dynamics of the heat transfer fluid inside the different pipe sections of the hydronic system with varying fluid flow rate. It is assumed that at each time step, the inlet fluid volume pushes all the other fluid cells inside the pipe section towards the outlet. There is no mixing or heat exchange in between adjacent fluid cells in the pipe. When the number of fluid cells reaches the maximum limit (200 for the GSHE), the two adjacent cells with the smallest temperature difference are merged together (Johra, 2018).

Similarly to the GSHE, the heat transfer taking place through the heat exchanger coil inside the water storage tank is calculated with the $\varepsilon$-NTU method (Bergman et al., 2011). The heat transfer from the MCHP circuit to the hot water is calculated for each fluid cell in the lower half of the storage tank.

The hot water storage tank is simulated with a modified version of the "plug-flow" model. The inlet fresh cold water at the bottom of tank pushes the other fluid cells up towards the outlet hot water draw-off on the top of the tank. It is assumed that there is no mixing in the tank, but there is heat transfer by conduction in between adjacent cells. The heat losses coefficient between each cell and the ambient environment at $22{ }^{\circ} \mathrm{C}$ is constant. A maximum of 2000 fluid cells can be placed in the "plug flow" model of the storage tank.

Pressure losses in the hydronic system are calculated with the Darcy-Weisbach equation. All thermo-physical properties of the heat transfer fluids (thermal conductivity, convective heat transfer coefficient, density, specific heat capacity, viscosity, etc.) are calculated as a function of composition, velocity and temperature, based on manufacturer's documentation (Johra, 2018).

\section{Results and discussion}

The different cascaded MCHP configurations presented before are firstly tested at different constant nominal total fluid flow rates ranging from $50 \mathrm{~L} / \mathrm{h}$ to $5000 \mathrm{~L} / \mathrm{h}$. The DHW draw-off is kept constant at $4 \mathrm{~L} / \mathrm{h}$ (97 L/day). Depending on the MCHP power output, the brine temperature from the ground source was varying between around $7{ }^{\circ} \mathrm{C}$ and $10{ }^{\circ} \mathrm{C}$. The average fluid temperature outlet, useful heating power output and COP are calculated over a test period of one month. The COP of the magnetic heating system is calculated as the ratio between the useful heating power output delivered to the water inside the storage tank, and the sum of all operational work, including motor work, pumping work and power use of the valves:

$$
C O P=\frac{Q_{\text {heating }}}{W_{\text {pump }}+W_{\text {motor }}+W_{\text {valves }}}
$$

One can see in Figure 7 that the cascaded MCHP configurations can produce an appreciable temperature span allowing the production of DHW at the required temperature target of $60{ }^{\circ} \mathrm{C}$. Above a certain fluid flow rate, the output temperature of the MCHP drops dramatically, which is typical behaviour for AMR-based systems (Johra et al., 2019a).

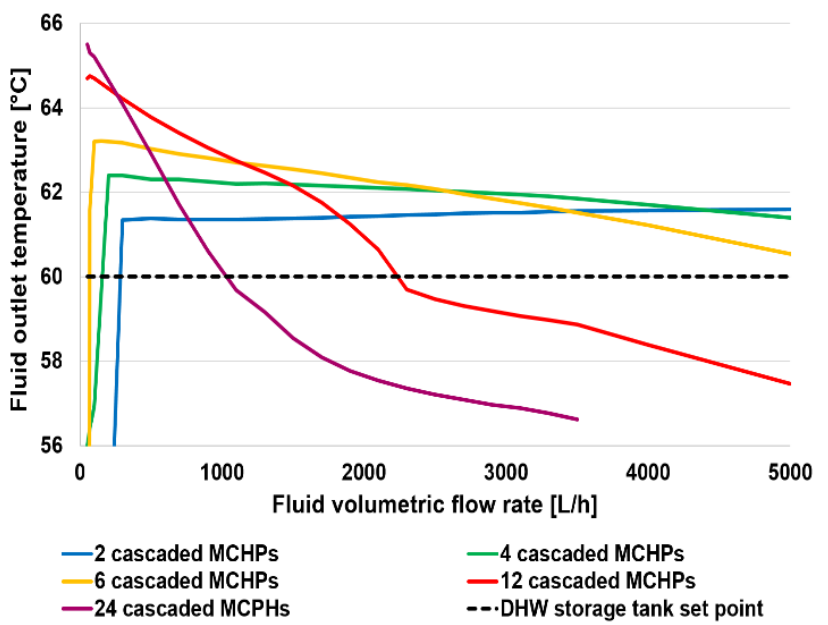

Figure 7: Outlet fluid temperature of cascaded MCHP configurations as a function of heat pump total fluid volumetric flow rate.

Similarly, the Figure 8 illustrates the increase of heating power output with the increase of fluid flow in the MCHP before its fall when the fluid outlet temperature drops.

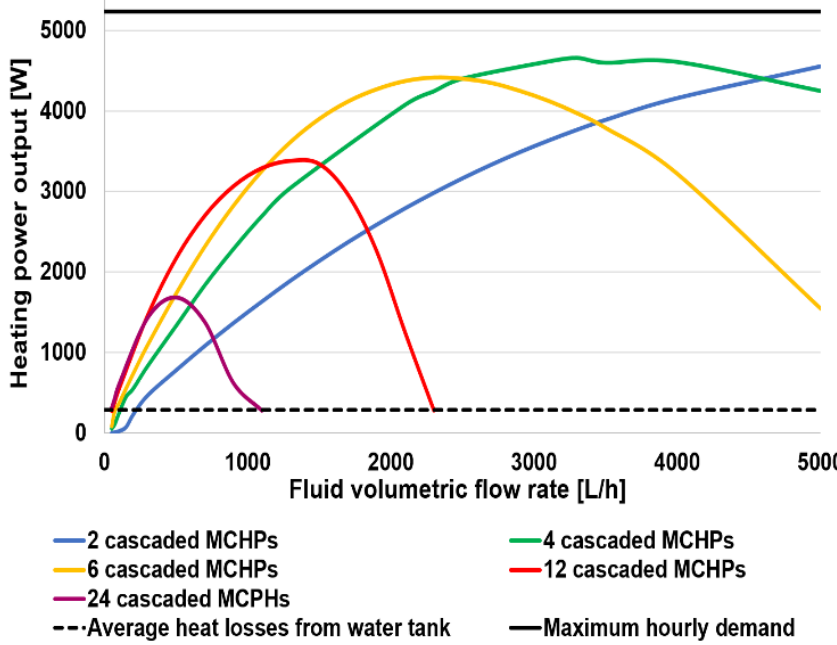

Figure 8: Useful heating power output of cascaded MCHP configurations as a function of heat pump total fluid volumetric flow rate. 
One can observe in Figure 9 that most of the cascaded MCHP configurations reaches appreciable COPs between 2 and 3 at a specific optimum fluid flow rate.

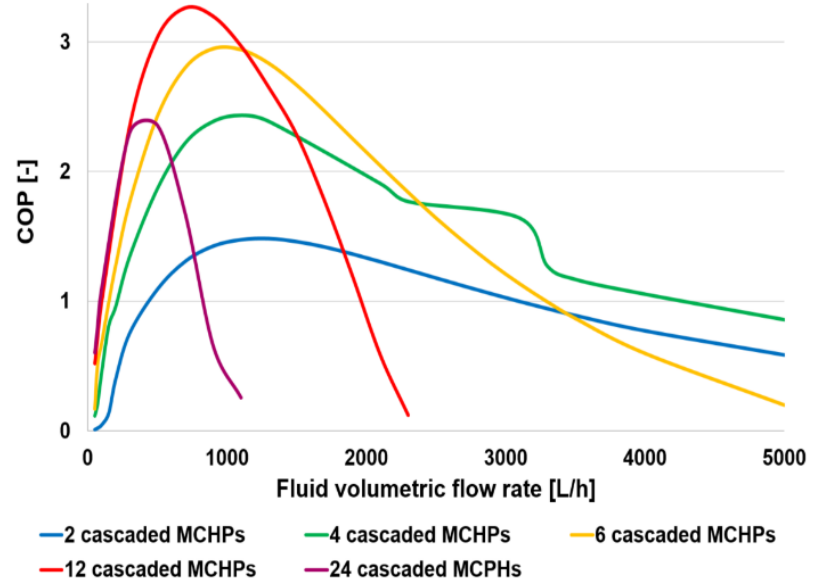

Figure 9: COP of cascaded MCHP configurations as a function of heat pump total fluid volumetric flow rate.

In a second time, the different cascaded MCHP configurations are tested at optimum fluid flow rate (with regards to COP) with the realistic hot water drawoff profile of the Danish single-family house during the month of September 2018. The optimum fluid flow rate for each cascading configuration is presented in Table 1.

Table 1: Selected optimum fluid flow rates for the different cascaded MCHP configurations.

\begin{tabular}{|c|c|}
\hline Cascading configuration & Optimum fluid flow \\
\hline 2 cascaded MCHPs & $1200 \mathrm{~L} / \mathrm{h}$ \\
\hline 4 cascaded MCHPs & $1100 \mathrm{~L} / \mathrm{h}$ \\
\hline 6 cascaded MCHPs & $900 \mathrm{~L} / \mathrm{h}$ \\
\hline 12 cascaded MCHPs & $700 \mathrm{~L} / \mathrm{h}$ \\
\hline 24 cascaded MCHPs & $500 \mathrm{~L} / \mathrm{h}$ \\
\hline
\end{tabular}

One can see in Figure 10 the temperature distribution of the DHW draw-off during the one-month test period. Apart from the 2 cascaded MCHPs configuration, all the other magnetic heating systems manage to provide DHW at temperatures above $55{ }^{\circ} \mathrm{C}$, which is suitable for domestic use without risk of legionella bacteria growth.

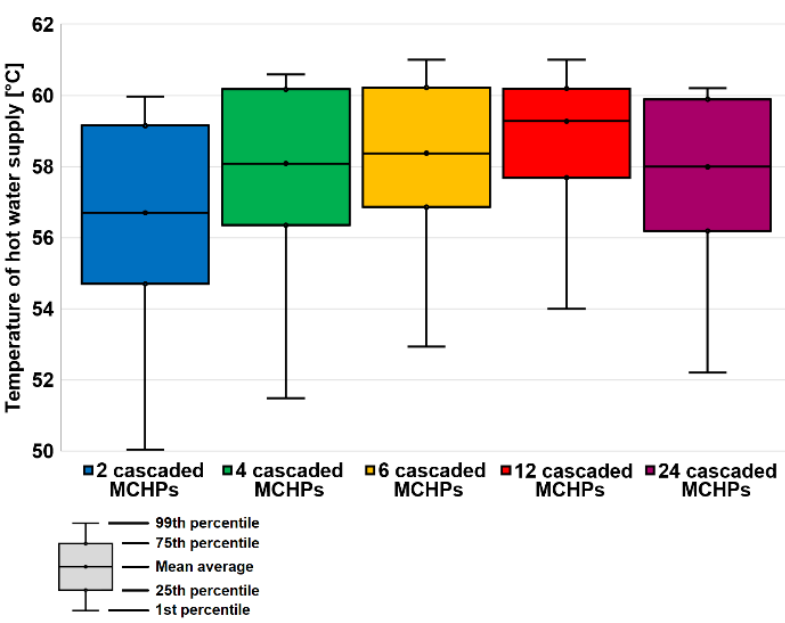

Figure 10: Box plot diagram of the DHW draw-off temperature distribution for the different MCHP configurations during the one-month test period.
The Figure 11 illustrates the performance of the different cascading configurations over the one-month test period. The COP is calculated here with a 60 -second running average. Similarly to the results presented in Figure 9, the 12 cascaded MCHPs configuration is the one with the best COP (mean average, $25^{\text {th }}$ percentile and $75^{\text {th }}$ percentile are $2.78,2.18$ and 3.26 , respectively). These results are quite promising as the average COP of the best performing magnetic heating system is comparable with the one of conventional ground source heat pumps used for DHW production: typically in the range of $2.2-$ 3.0 (Niemelä et al., 2018).

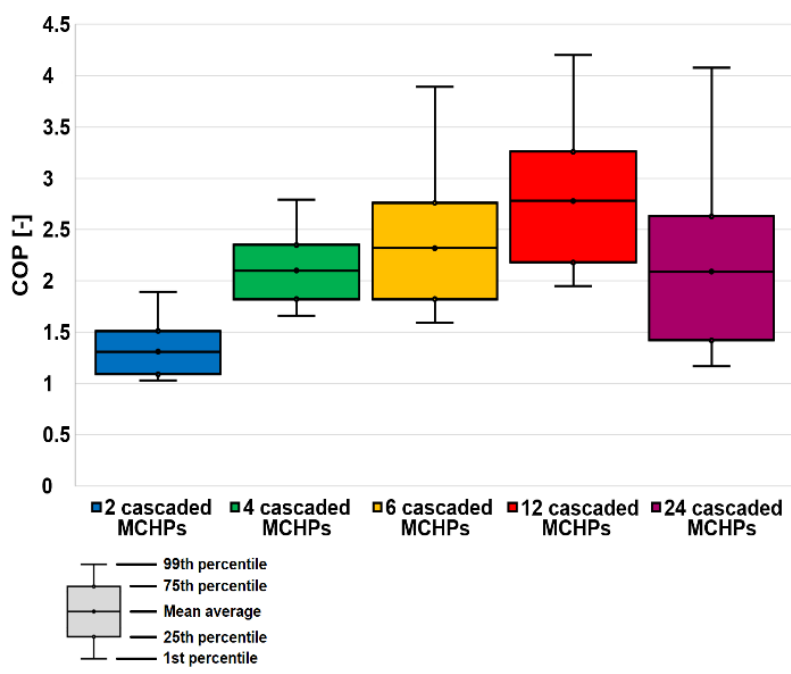

Figure 11: Box plot diagram of the COP distribution for the different MCHP configurations during the onemonth test period.

\section{Conclusion}

This article presented an innovative magnetocaloric heat pump system for domestic hot water production. Because of the reversible nature of the magnetocaloric effect which is at core of the magnetic heating systems, the latter have the potential for very high coefficient of performance. Such a system has already demonstrated its ability to provide for the indoor space heating needs of low energy buildings. However, the restricted temperature span generated by magnetic heating systems is a serious limitation for high temperature purposes such as domestic hot water production.

To overcome this issue, the authors have suggested the use of cascaded magnetocaloric heat pumps to generate a temperature span greater than $50 \mathrm{~K}$ between a ground source heat exchanger and a hot water storage tank. The results of the current numerical study show that cascaded magnetocaloric heat pump configurations can produce hot water with temperatures above $60{ }^{\circ} \mathrm{C}$ and up to $65^{\circ} \mathrm{C}$. In addition, most of the tested magnetic heating systems were able to provide for the hot water needs of a single-family house in Denmark. With a monthly average COP of 2.78, the best performing magnetic heating system is thus as energy efficient as conventional vapour compression heat pumps used for DHW production. 
Cascading magnetocaloric heat pumps thus appears to be a viable solution for the DHW production. However, this technology has yet to prove its competitiveness against conventional heat pump systems. Further research is needed to improve the design and performance of magnetic heating prototypes. More experimental tests should be performed for building applications with fullscale setups and realistic boundary conditions. A number of fundamental research and engineering challenges are to be addressed to develop new magnetocaloric materials, optimum control strategies, and efficient hydronic configurations minimizing parasitic heat losses and pressure drops.

\section{Acknowledgement}

This work was financed by the ENOVHEAT project, which is funded by Innovation Fund Denmark (contract no 12-132673).

\section{References}

Aprea, C., Greco, A. and Maiorino, A. (2015). GeoThermag: a geothermal magnetic refrigerator. International Journal of Refrigeration 59, 75-83.

Bahl, C.R.H. (2015). ENOVHEAT project summary: development of efficient novel magnetocaloric heat pumps. http://www.enovheat.dk/Research/ProjectSummary

Barclay, J.A. and Steyert, W.A. (1982). US Patent US4332135.

Bergman, T.L., Lavine, A.S., Incropera, F.P. and DeWitt, D.P. (2011). Fundamentals of heat and mass transfer ( $7^{\text {th }}$ edition). Wiley. Hoboken (USA).

Cockroft, J. and Kelly, N. (2006). A comparative assessment of future heat and power sources for the UK domestic sector. Energy Conversion and Management 47, 2349-2360.

Engelbrecht, K. (2008). A numerical model of an active magnetic regenerator refrigerator with experimental validation. Ph.D. thesis. University of Wisconsin. Madison (USA).

Engelbrecht, K., Eriksen, D., Bahl, C.R.H., Bjørk, R., Geyti, J., Lozano, J.A., Nielsen, K.K., Saxild, F., Smith, A. and Pryds, N. (2012). Experimental results for a novel rotary active magnetic regenerator. International Journal of Refrigeration 35, 14981505 .

Filonenko, K., Johra, H., Dall'Olio, S., Engelbrecht, K., Heiselberg, P., Bahl, C. \& Veje, C. (2018). Simulation of a magnetocaloric heating network. Proceedings from $8^{\text {th }}$ International Conference on Caloric Cooling (thermag VIII). Darmstadt (Germany), 16-20 September 2018.

Fischer, D. and Madini, H. (2017). On heat pumps in smart grids: A review. Renewable and Sustainable Energy Reviews 70, 342-357.

Fuentes, E., Arce, L. and Salom, J. (2018). A review of domestic hot water consumption profiles for application in systems and building energy performance analysis. Renewable and Sustainable Energy Reviews 81, 1530-1547.

Goetzler, W., Zogg, R., Young, J. and Johnson, C. (2014). Energy savings potential and RD\&D opportunities for non-vapor compression HVAC technologies. U.S. Department of Energy, Building Technologies Office.

Jacobs, S., Auringer, J., Boeder, A., Chell, J., Komorowski, L., Leonard, J., Russek, S. and Zimm, C. (2014). The performance of a large-scale rotary magnetic refrigerator. International Journal of Refrigeration 37, 84-91.

Johra, H. (2018). Integration of a magnetocaloric heat pump in energy flexible buildings. Ph.D. thesis. Aalborg University. Aalborg (Denmark).

Johra, H., Filonenko, K., Heiselberg, P., Veje, C., Lei, T., Dall'Olio, S., Engelbrecht, K. and Bahl, C. (2018). Integration of a magnetocaloric heat pump in a low-energy residential building. Building Simulation: An International Journal 11, 753-763.

Johra, H., Filonenko, K., Heiselberg, P., Veje, C., Dall'Olio, S., Engelbrecht, K. and Bahl, C. (2019a). Integration of a magnetocaloric heat pump in an energy flexible residential building. Renewable Energy 136, 115-126.

Johra, H., Filonenko, K., Heiselberg, P., Veje, C., Dall'Olio, S., Engelbrecht, K. \& Bahl, C. (2019b). Cascading implementation of a magnetocaloric heat pump for building space heating applications. Proceedings from $10^{\text {th }}$ International Conference on System Simulation in Buildings. Liege (Belgium), 1012 December 2018.

Kitanovski, A., Tušek, J., Tomc, U., Plaznik, U., Ožbolt, M., and Poredoš, A. (2015). Magnetocaloric Energy Conversion: From Theory to Applications. Springer International Publisher. New York (USA).

Lei, T., Engelbrecht, K., Nielsen, K.K. and Veje, C.T. (2017). Study of the geometries of active magnetic regenerators for room temperature magnetocaloric refrigeration. Applied Thermal Engineering, 111, 1232-1243.

Lei, T., Navickaitè, K., Engelbrecht, K., Barcza, A., Vieyra, H., Nielsen, K.K. and Bahl, C.R.H. (2018). Passive characterization and active testing of epoxy bonded regenerators for room temperature magnetic refrigeration. Applied Thermal Engineering 128, 10 19.

Lund, H., Möller, B., Mathiesen, B.V. and Dyrelund, A. (2010). The role of district heating in future renewable energy systems. Energy 35, 1381-1390.

Mañosa, L., González-Alonso, D., Planes, A., Bonnot, E., Barrio, M., Tamarit, J.L., Aksoy, S. and Acet, M. (2010). Giant solid-state barocaloric effect in the $\mathrm{Ni}-$ 
Mn-In magnetic shape-memory alloy. Nature Materials 9, 478-481.

Navickaitè, K., Neves Bez, H., Lei, T., Barcza, A., Vieyra, H., Bahl, C.R.H., and Engelbrecht, K. (2018). Experimental and numerical comparison of multi-layered $\mathrm{La}(\mathrm{Fe}, \mathrm{Si}, \mathrm{Mn}) 13 \mathrm{Hy}$ active magnetic regenerators. International Journal of Refrigeration 86, 322-330.

Niemelä, T., Manner, M., Laitinen, A., Sivula, T.M., Jokisalo, J. and Kosonen, R. (2018). Computational and experimental performance analysis of a novel method for heating of domestic hot water with a ground source heat pump system. Energy and Buildings 161, 22-40.

Nowak, T. and Westring P. (2015). European Heat Pump Market and Statistics Report 2015. The European Heat Pump Association AISBL (EHPA).

Palzer, A. and Henning, H.M. (2014). A comprehensive model for the German electricity and heat sector in a future energy system with a dominant contribution from renewable energy technologies - Part II: Results. Renewable and Sustainable Energy Reviews 30, 1019-1034.

Plaznik, U., Vrabelj, M., Kutnjak, Z., Malič, B., Rožič, B., Poredoš, A. and Kitanovski, A. (2019).
Numerical modelling and experimental validation of a regenerative electrocaloric cooler. International Journal of Refrigeration 98, 139-149.

Self, S.J., Reddy, B.V. and Rosen, M.A. (2013). Geothermal heat pump systems: Status review and comparison with other heating options. Applied Energy 111, 341-348.

Smith, A., Bahl, C.R.H., Bjørk, R., Engelbrecht, K., Nielsen, K.K. and Pryds, N. (2012). Materials challenges for high performance magnetocaloric refrigeration devices. Advanced Energy Materials 2, 1288-1318.

Tušek, J., Engelbrecht, K., Millán-Solsona, R., Mañosa, L., Vives, E., Mikkelsen, L.P. and Pryds, N. (2015). The elastocaloric effect: a way to cool efficiently. Advanced Energy Materials 5, 1500361.

Weiss, P. and Piccard, A. (1918). Sur un nouveau phénomène magnétocalorique. Comptes Rendus Acad. Sci. (Paris) 166, 352-354.

Østergaard, P.A. and Andersen, A.N. (2018). Economic feasibility of booster heat pumps in heat pump-based district heating systems. Energy 155, 921-929. 